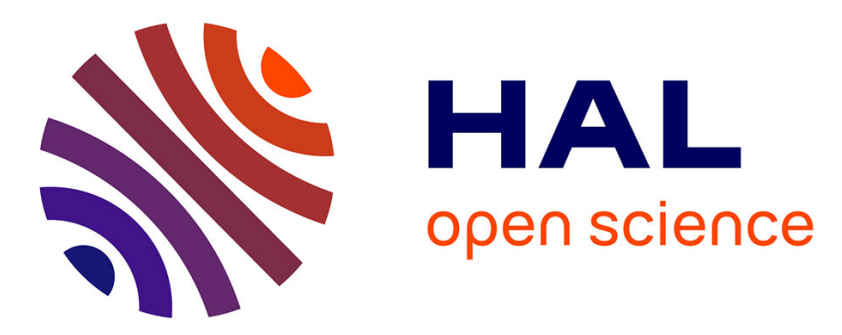

\title{
Communication in the second and third year of life: Relationships between nonverbal social skills and language
}

\author{
Hélène Cochet, Richard W Byrne
}

\section{To cite this version:}

Hélène Cochet, Richard W Byrne. Communication in the second and third year of life: Relationships between nonverbal social skills and language. Infant Behavior and Development, 2016, 44, pp.189-198. 10.1016/j.infbeh.2016.07.003 . halshs-01464545

\section{HAL Id: halshs-01464545 \\ https://shs.hal.science/halshs-01464545}

Submitted on 11 Jul 2017

HAL is a multi-disciplinary open access archive for the deposit and dissemination of scientific research documents, whether they are published or not. The documents may come from teaching and research institutions in France or abroad, or from public or private research centers.
L'archive ouverte pluridisciplinaire HAL, est destinée au dépôt et à la diffusion de documents scientifiques de niveau recherche, publiés ou non, émanant des établissements d'enseignement et de recherche français ou étrangers, des laboratoires publics ou privés. 
Full length article

\title{
Communication in the second and third year of life: Relationships between nonverbal social skills and language
}

\author{
Hélène Cochet ${ }^{\mathrm{a}, *}$, Richard W. Byrne ${ }^{\mathrm{b}}$ \\ a CLLE, Toulouse University, CNRS, UT2J, 5 Allées Antonio Machado, 31058 Toulouse Cedex 9, France \\ b School of Psychology \& Neuroscience, Centre for Social Learning E Cognitive Evolution, St Andrews, United Kingdom
}

\section{A R T I C L E I N F O}

\section{Article history:}

Received 24 June 2015

Received in revised form 23 February 2016

Accepted 7 July 2016

\section{Keywords:}

Development of communication

Gestures

Language

Toddlers

\begin{abstract}
A B S T R A C T
We aimed to investigate developmental continuities between a range of early social and communicative abilities (including gestural communication) and language acquisition in children aged between 11 and 41 months. Initiation of joint attention and imitation were strongly correlated to language comprehension and production. Moreover, the analysis of different communicative gestures revealed significant relationships between language development and the production of symbolic gestures, declarative pointing (declarative informative pointing in particular), and head nodding. Other gestures such as imperative pointing, showing, and head shaking were not found to correlate with language level. Our results also suggest that distinct processes are involved in the development of language comprehension and production, and highlight the importance of considering various characteristics of children's early communicative skills.
\end{abstract}

(C) 2016 Elsevier Inc. All rights reserved.

The ability to interact intentionally with a communicative partner emerges early in human development, before language acquisition, and infants' social interactions gradually exhibit increasing coordination of attention with others (e.g., Carpenter, Nagell, \& Tomasello, 1998). Moreover, it has been shown that joint attention skills assessed in the second year of life are closely associated with later, higher-order social skills (e.g., Kristen, Sodian, Thoermer, \& Perst, 2011; Vaughan Van Hecke et al., 2007), in particular theory of mind abilities (e.g., Charman et al., 2000). Because it shapes infants' social and linguistic environment, gestural communication may have a privileged role in these developmental relationships. The degree of proficiency in the use of communicative gestures has been especially claimed to predict language comprehension and production (e.g., Colonnesi, Stams, Koster, \& Noom, 2010). However, the characteristics of the language-gesture relationship may vary according to the nature of gestures, starting with the classical distinction between symbolic and deictic gestures (e.g., Liszkowski, 2008). The production of symbolic gestures, which decreases as speech develops (e.g., Acredolo \& Goodwyn, 1988; Rodrigo et al., 2006), has been argued to facilitate the early stages of language acquisition (e.g., Goodwyn, Acredolo, \& Brown, 2000); whereas pointing gestures may play a primary role in different milestones of language development, including in the ability to combine several words (e.g., Capirci, Iverson, Pizzuto, \& Volterra, 1996; Rowe \& Goldin-Meadow, 2009), explaining why the frequency of pointing, produced in combination with words or vocalizations, increases during the second year of life (e.g., Özçaliskan \& Goldin-Meadow, 2005; Guidetti, 2002).

In addition, a pointing gesture can convey different meanings, depending on the context and on whether the pointing serves an imperative or declarative function (e.g., Bates, Camaioni, \& Volterra, 1975; Tomasello, Carpenter, \& Liszkowski, 2007). Imperative pointing is used to obtain an object or to request a specific action from the adult (Colonnesi, Rieffe, Koops,

\footnotetext{
* Corresponding author.

E-mail addresses: helene.cochet@univ-tlse2.fr (H. Cochet), rwb@st-andrews.ac.uk (R.W. Byrne).
} 
\& Perucchini, 2008), while the goal of declarative pointing is to share an interest with the recipient about an object, event or location (declarative expressive pointing, Liszkowski, Carpenter, Henning, Striano, \& Tomasello, 2004) or to provide the recipient with information he/she needs about a specific referent (declarative informative pointing, Liszkowski, Carpenter, \& Tomasello, 2008). The difference between the imperative and declarative functions of pointing has been supported by the study of behavioural markers such as hand shape, hand preference and vocalizations (Cochet, Jover, Oger, \& Vauclair, 2014; Cochet \& Vauclair, 2010; Liszkowski \& Tomasello, 2011), which suggests that the two types of pointing may have distinct origins. Imperative pointing has been hypothesized to develop from non-communicative reaching actions (e.g., Cochet et al., 2014) through a process of ontogenetic ritualization (Tomasello \& Call, 1997), while the development of declarative pointing may rely on early social-cognitive abilities, including imitation abilities (Camaioni, Perucchini, Bellagamba, \& Colonnesi, 2004). The hypothesis of distinct origins of imperative and declarative pointing raises the question of their respective roles in language acquisition. Distinguishing between the different functions of pointing is therefore necessary to investigate further the relationship between gestures and language development and determine to what extent this relationship concerns declarative gestures, and especially informative pointing, rather than imperative ones. Declarative informative pointing seems to share several characteristics with language, by both contributing to and reflecting (1) the understanding of others' attentional and knowledge states (Meng \& Hashiya, 2014) and (2) the development of cooperation abilities (e.g., Brownell, Ramani, \& Zerwas, 2006; Liszkowski, 2005). In addition, theory of mind abilities (ToM), measured with standard tasks (e.g., Sally-Ann test) in children between 3 and 4 years of age, appear to be significantly related to the production of informative pointing, but not to the production of expressive pointing (Cochet, Jover, Rizzo, \& Vauclair, 2016). Although little is known about the role of informative pointing at earlier stages of development, the production of this gesture during toddlerhood might be closely associated with the development of language and ToM.

The goal of the present study was thus to investigate, with a mixed longitudinal design involving two sessions, whether advancement in early communicative skills was significantly associated with the later emergence of language. While several studies have highlighted the existence of close links between early joint attention skills and language acquisition (e.g., Colonnesi et al., 2008), to our knowledge there have been no studies so far focusing at the same time (1) on several dimensions of social and communicative development, such as joint attention, gestural communication, imitation and cooperation abilities and (2) on several communicative gestures, including different functions of pointing. We therefore aimed at exploring the relationships between gestural communication (focusing especially on imperative, declarative-expressive and declarativeinformative pointing, as well as on symbolic gestures), language development (by differentiating comprehension from production), and social and cognitive abilities like imitation and joint attention (by distinguishing between children's initiating and responsive behaviours). We investigated the dynamics of these relationships both at the same point in time and across development in children from 11 to 41 months of age.

Based on previous work, reviewed above, we expected: joint attention and imitation abilities might correlate with the production of symbolic gestures and declarative pointing, but not with the production of imperative pointing. Early use of declarative pointing (declarative informative pointing in particular) might correlate with language comprehension and production, whereas early use of imperative pointing might not correlate with language development, or with language comprehension only; the production of declarative informative pointing might also correlate with the development of cooperative abilities. More generally, children's responsive behaviours might correlate with language comprehension while children's initiating behaviours might correlate with both language comprehension and production.

\section{Method}

\subsection{Participants}

Fourteen children ( 3 boys and 11 girls) were tested with their mother in the Baby and Child Lab (https://developmentlab.wp.st-andrews.ac.uk) of the School of Psychology in the University of St Andrews. They were recruited in day nurseries, in parent \& toddler groups and through advertisement via the Baby and Child Lab website. One child was finally excluded from the data because her language score reached the maximum of the scale used, and may therefore not have been representative of her actual linguistic abilities. Eight children were tested twice. For their first visit, children were between 11 and 33 months of age $(N=13 ; M=21$ months 8 days; $S D=7$ months 6 days). Eight of these came back for the second visit about 10 months later ( $M=10$ months 14 days; $S D=1$ month 5 days), when they were between 21 and 41 months of age ( $N=8 ; M=29$ months 9 days; $S D=7$ months 1 day). The 5 other children could not come for the second visit due to moving house or other reasons for unavailability.

\subsection{Procedure}

Prior to the experiment, the experimenter explained the research goals to the parents in the testing room, who then completed an informed consent form and filled in the parental questionnaires. Meanwhile, the child was encouraged to familiarize himself/herself with his/her environment. Most of them were seated on cushions on the floor and played with toys offered by the experimenter. The parent was then encouraged to interact with his/her child during this warm-up period to make him/her feel secure. For those children who could be tested twice, the procedure was identical for the two sessions (T1 and T2). 
Table 1

Description of the situations eliciting showing gestures, symbolic gestures and pointing gestures (see also the Communicative gestures paragraph in the Measures section).

\begin{tabular}{|c|c|}
\hline Gesture & Eliciting situation \\
\hline Showing gestures & $\begin{array}{l}\text { After the child had been given an object (in the imperative pointing task, for example), the experimenter } \\
\text { verbally expressed some interest in the object so that the child held it up in the experimenter's line of sight. To } \\
\text { distinguish between showing gesture and giving/offering action, the experimenter did not request or extend } \\
\text { her arm toward the object. Instances in which the child prolonged his/her gesture to give the object to the } \\
\text { adult were coded as "giving actions". }\end{array}$ \\
\hline Symbolic gestures & $\begin{array}{l}\text { Several situations involving puppets were used to elicit waving gesture as a greeting (the hand is raised } \\
\text { towards the recipient and possibly moves to and fro), no gesture to ask the puppet not to do something stupid } \\
\text { (the whole hand or the index finger is raised and oscillates from right to left), hush gesture to ask for silence } \\
\text { (the index finger is placed over the mouth), and thumb up gesture in approval (the closed fist is held with the } \\
\text { thumb extended upward). }\end{array}$ \\
\hline Imperative pointing & $\begin{array}{l}\text { The experimenter handled an attractive toy and put it on the table, beyond the child's reach. The } \\
\text { experimenter showed interest in the toy and gave it to the child if the latter produced a pointing gesture. If the } \\
\text { child did not produce any gesture within } 15 \mathrm{~s} \text {, the trial was over. Different toys were used for the } 4 \text { trials. }\end{array}$ \\
\hline Declarative expressive pointing & $\begin{array}{l}\text { Declarative expressive situations are characterized by a surprising and/or interesting object or event that the } \\
\text { child wants to indicate to the experimenter to share his/her enthusiasm. We used out of reach wind-up toys } \\
\text { that were activated, as a surprise, by the experimenter during testing. When the child produced a pointing } \\
\text { gesture, the experimenter emoted positively about the referent for a few seconds but did not give the toy to } \\
\text { the child. }\end{array}$ \\
\hline Declarative informative pointing & $\begin{array}{l}\text { The experimenter pretended to need a specific object that she had been using earlier in the session. We used } \\
\text { everyday objects (i.e., a pen, a small scarf, a phone, glasses) that we thought would not be particularly } \\
\text { attractive to the children, or at least, not as interesting as the toys used for the imperative task. The } \\
\text { experimenter first glanced around the room and verbalized a sentence such as "where did I leave my } \\
\text { glasses?", without directly speaking to the child and without looking at him/her. When the child pointed } \\
\text { toward the object, the experimenter retrieved it and thanked the child for his/her help. If no pointing was } \\
\text { produced within } 15 \mathrm{~s} \text {, the experimenter directly asked the child "Have you seen my glasses?" and waited for } \\
\text { the child's reaction for a further } 10 \text { s. }\end{array}$ \\
\hline
\end{tabular}

During testing, children were seated at a table on a chair (child-sized furniture was used), across from the experimenter who was kneeling on the floor to remain at the child's level. Parents were asked to remain silent and not to initiate communicative behaviour toward their child, but they could intervene if the latter showed any sign of disengagement. A set of 25 semi-structured communicative situations based on the abridged Early Social Communication Scale (ESCS, Mundy et al., 2003; see also Guidetti \& Tourrette, $2009^{1}$ and Seibert, Hogan, \& Mundy, 1982) were set up to elicit interactions between the child and the experimenter (see the Measures and material section for a complete description). These situations required between 15 to $25 \mathrm{~min}$ to be administered. Although some of them were likely to elicit communicative gestures, we set up additional situations in contexts of shared activities to collect further data on gestural communication: we focused on the main gestures produced by children under the age of 4, namely pointing gestures (distinguishing between: imperative, declarative expressive and declarative informative), showing gestures, and symbolic gestures. Eliciting situations, based on previous studies (Blake, O'Rourke, \& Borzellino, 1994; Cochet \& Vauclair, 2010) are described in Table 1. Four trials were administered for each category of gestures, leading to a total of 20 trials in each session, distributed across the whole session in order to preserve natural communicative contexts and avoid repetitive behaviours. The order of the 20 trials was counterbalanced between children. We also recorded gestures produced by the children in response to the communicative situations from ESCS, so that the number of gestures produced could be analysed as a dependent variable. Definitions and details of operationalization are given for each gesture in the Measures section.

All sessions were videotaped. The video camera was oriented to enable the recording of a three-quarter to full-face view of the child as well as a profile view of the experimenter. Approval for this research has been obtained from the Ethics Committee of the School of Psychology.

\subsection{Measures and material}

Language level. The British version of the MacArthur Communicative Development Inventories (MCDI, Hamilton, Plunkett, \& Schafer, 2000; see also Fenson et al., 2007) was used to assess language level. This parental questionnaire assessed the number of words understood and the number of words spoken and understood by the child (out of the 614 words examined in the questionnaire). More detailed analyses can be performed by distinguishing linguistic categories, for example nouns from prepositions or pronouns. The raw scores corresponded to the total number of words understood and to the total number of words understood and produced by the child. This questionnaire is conventionally used for children up to 30 months, but it was considered a valid measure even for slightly older children, as there was no ceiling effect in the scores obtained (the children included in the final sample did not reach the maximum score, in any of the sessions).

\footnotetext{
${ }^{1}$ ESCP is a communication scale designed for toddlers, initially validated in a French population. It allows for a distinction between different categories of verbal and nonverbal communicative behaviours and different roles played by the children in the interaction.
} 
Table 2

Description of the different behavioural categories used in the abridged ESCS (Mundy et al., 2003).

\begin{tabular}{ll}
\hline Category & Examples of the child's behaviours \\
\hline Initiating Joint Attention (IJA) & Gaze alternation between the object and the experimenter, pointing, showing \\
Responding to Joint Attention (RJA) & Gaze following, point following \\
Initiating Behaviour Requests (IBR) & Imperative pointing (out-of-reach object), request to activate the mechanical toy after it had stopped. \\
Responding to Behaviour Requests (RBR) & Follow commands \\
Initiating Social Interactions (ISI) & Initiates turn-taking, song, or tickle \\
Responding to Social Interactions (RSI) & Responds to turn-taking, responds to invitation \\
\hline
\end{tabular}

Social interaction skills. Several toys and objects (e.g., ball, car, picture book, mechanical toys, hat, glasses, comb) were used for the ESCS standardized situations, thus allowing comparison across children. Behaviours were coded from videotaped records and classified into six categories according to (1) the child's communicative goal and (2) whether the child initiated or responded to the interaction. Communicative goals described in the ESCS are divided into three categories, defined as follows (Guidetti \& Tourrette, 2009; Mundy et al., 2003): (a) joint attention behaviours when children share experience of objects or events with the adult, (b) behavioural requests when children seek to obtain an object or a specific action from the adult, and (c) social interaction behaviours when children seek to engage in playful and happy turn taking with the adult. Examples of behaviours included in each category are presented in Table 2. Six scores were thus obtained, corresponding to the number of behaviours observed in the different categories.

In addition, we set up a parental questionnaire to get further measures of children's social and communicative behaviours (see Appendix 1), which may be useful in cases when the child does not interact with the experimenter as willingly as he/she does with his/her parents. Parents were asked to answer 13 yes-or-no questions divided into three sections: imitation skills, gestural communication, and cooperative behaviours. The score corresponded to the total number of yes-responses, a higher score indicating higher skills. Sub-scores were also calculated for each section.

Communicative gestures. Pointing was defined in the present study as the extension of the arm and the hand (with all fingers extended or only the index finger) toward an object, event or location. By contrast, symbolic gestures (e.g., nodding the head, waving "goodbye") have a more arbitrary relationship with their objects, based on conventionality or habit (see Table 1 for more complete definitions). To make sure that the gestures produced were communicative and intentional, several criteria were used: (1) the gesture had to be produced and directed toward a recipient, (2) the gesture was accompanied by visual-orienting behaviours, including gaze alternation between the recipient and the object or event being referred to, and (3) children were likely to repeat their gesture if they fail to produce the desired effect on their communicative partner (e.g., Meguerditchian, Cochet, \& Vauclair, 2011). Instances that did not meet at least one of these criteria, both in situations from ESCS and gestural communication tasks, were not included in the analyses. Moreover, to determine children's communicative intention when they produced a gesture, we noted the behaviour that followed the adult's first reaction to their signal. Children may display signs of dissatisfaction and repeat their gesture if they do not achieve their goal the first time around (e.g., Liszkowski et al., 2004). If children seemed dissatisfied when the adult commented on the object or event of interest in the declarative pointing tasks (i.e., if they whined, cried, and/or prolonged or repeated their pointing gesture), we inferred that their motive was imperative rather than declarative (Carpenter et al., 1998; Cochet \& Vauclair, 2010). We also used these criteria for the experimental pointing situations (see above). If the function of the gesture did not match the different pointing situations, or if it could not be clearly established, the gesture was not taken into account for the analyses.

Hand shape. Pointing was coded as index-finger gesture when the index finger was extended and the other fingers tightly or more lightly curled, and as whole-hand gesture when all the fingers were extended without any finger clearly distinct from the others.

\subsection{Inter-observer reliability}

An additional coder, blind to the research objectives, rated 4 of the 21 videos obtained in total (19\%). Cohen's kappa coefficients for the intentionality of gestures, the category of gestures, the function of pointing, and hand shape of pointing were $0.82,0.96,0.79$, and 0.86 , respectively. Coefficients for the six categories of the ESCS (see Table 2) varied between 0.73 and 0.92 .

\subsection{Analyses}

Two series of analyses were performed: first, we examined overall relationships between variables of interest at T1 ( $N=13$; we did not perform these analyses at T2 due to the smaller sample size, $N=8$ ). Second, we performed longitudinal analyses between T1 and T2 $(N=8)$. For each series of analyses, we focused on the relationship between social-cognitive skills (parental questionnaire scores and ESCS scores), gestural communication and language. As most of our variables were not normally distributed, we used non-parametric tests, including Spearman's rank correlations, Wilcoxon signed-rank tests, and Mann-Whitney $U$ tests. 


\section{Results}

\subsection{Relationships between social skills, gestures and language at T1 $(N=13)$}

To get an overview of the development of gestural communication, we first performed Spearman's rank correlations between age and the number of gestures produced. The numbers of showing gestures, imperative pointing gestures and head shakes did not significantly change with age. By contrast, the production of declarative pointing was positively correlated with age (both expressive pointing, $r s=0.77 ; p<0.01$, and informative pointing, $r s=0.83 ; p<0.001$ ), as did the production of symbolic gestures $r s=0.56 ; p<0.05)$, and head nods $(r s=0.73 ; p<0.01)$. Similar patterns were observed between the number of gestures produced and language level: the number of showing gestures, imperative pointing gestures and head shakes did not significantly change with level of language comprehension or production, whereas the production of informative pointing was positively correlated with both language production, $r s=0.77 ; p<0.01$, and comprehension, $r s=0.84 ; p<0.001$. The production of expressive pointing, symbolic gestures, and head nods were significantly correlated with language production $(r s=0.57 ; p<0.05 ; r s=0.59 ; p<0.05 ; r s=0.72 ; p<0.01$, respectively), but the correlations did not reach significance level for language comprehension ( $r s=0.55 ; p=0.051 ; r s=0.50 ; p=0.082 ; r s=0.53 ; p=0.62$, respectively).

Second, we focused on the relationship between the social skill variables assessed through the parental questionnaire (i.e., imitation, gestural communication, and cooperation) and communicative abilities. The production of gestures, each category being considered separately, was not found to correlate with any of the social skills scores. The gestural communication score was significantly correlated to language comprehension and production, $r s=0.60 ; p<0.05$ and $r s=0.70 ; p<0.01$, respectively; the imitation score was correlated to language production, $r s=0.74 ; p<0.01$, but not to language comprehension, $r s=0.53$; $p=0.06$; and correlations between the cooperation score and language measures were not significant, $r s=0.25 ; p=0.41$ for language comprehension, and $r s=0.19 ; p=0.54$ for language production.

Third, we analysed the relationships between the social skill variables assessed with the ESCS, the different types of gesture produced and language level. Initiation of joint attention score (IJA) was found to be correlated to language comprehension and language production, $r s=0.79 ; p<0.01$ and $r s=0.82 ; p<0.001$, respectively, whereas correlations were not significant for response to joint attention score (RJA), $r s=0.30 ; p=0.31$ and $r s=0.27 ; p=0.37$, respectively. Initiation of social interactions score (ISI) was correlated to language comprehension, $r s=0.68 ; p<0.01$, but not to language production, $r s=0.50 ; p=0.084$, and response to social interactions score (RSI) was correlated to language comprehension, $r s=0.72 ; p<0.01$, and language production, $r s=0.69 ; p<0.01$. As to the behaviour request category, only the response to behaviour request score (RBR) was significantly correlated to language comprehension, $r s=0.59 ; p<0.05$.

We did not analyse the relationships between the production of gestures and the six general ESCS categories, as some of these categories included measures of gestural communication, but analyses with sub-categories of ESCS revealed some significant correlations. The ability to follow the adult's pointing was positively correlated to the number of children's expressive pointing, $r s=0.79 ; p<0.01$, and informative pointing, $r s=0.68 ; p<0.01$. The frequency of gaze alternation between the adult and the object of interest was correlated to the number of head nods, $r s=0.78 ; p<0.01$, symbolic gestures, $r s=0.65$; $p<0.05$, informative pointing, $r s=0.63 ; p<0.05$, but correlations were not significant with the number of head shakes, $r s=0.21 ; p=0.49$, imperative pointing, $r s=0.08 ; p=0.79$, expressive pointing, $r s=0.49 ; p=0.086$. The frequency of point following and the frequency of gaze alternation between the adult and the referent were also correlated with language level (with language comprehension, $r s=0.74 ; p<0.01$ and $r s=0.72 ; p<0.01$, respectively, and with language production, $r s=.65$; $p<0.05$, and $r s=0.78 ; p<0.01$, respectively).

Form of pointing gestures. Mean percentages of index-finger gestures (and standard deviations) for imperative pointing $(N=13)$, declarative expressive pointing $(N=11)$, and declarative informative pointing $(N=7)$ were respectively $12.9 \%(12.8)$, $86.6 \%$ (29.5) and $92.9 \%$ (18.9). These percentages were significantly different between imperative and expressive gestures, $Z=2.80 ; p<0.01$, and between imperative and informative gestures $Z=2.37 ; p<0.05$. Spearman correlations revealed that the proportion of index-finger pointing, all functions taken into account, significantly increased with age, $r s=0.77 ; p<0.01$, and with language level (both with language comprehension, $r s=0.73 ; p<0.01$ and language production, $r s=0.84 ; p<0.001$ ). This result may reflect the increase in the amount of declarative pointing produced (mainly index-finger gestures) as children's age and language level increased (see above). Indeed, none of the correlations were significant when we considered each function of pointing separately, suggesting that imperative and declarative gestures were characterized by different hand shapes, which did not seem to change in the course of development.

The significant relationships observed at T1 are summarized in Fig. 1.

Line thickness reflects the strength of the correlations and the number of asterisks indicates significance level $\left({ }^{*} p<0.05\right.$; ${ }^{* *} p<0.01$; $\left.{ }^{* * *} p<0.001\right)$.

\subsection{Longitudinal analyses between $T 1$ and $T 2(N=8)$}

Mean language scores and mean number of gestures produced at T1 and T2 are presented in Table 3.

Wilcoxon signed ranks tests were used to compare the different abilities assessed during the first and second sessions. Language scores (both comprehension and production) were of course higher at T2 than at T1, for each linguistic category (nouns, verbs, adjectives and prepositions). Language comprehension at T1 was significantly correlated to both language comprehension and language production at T2 ( $r s=0.72 ; p<0.05$, and $r s=0.75 ; p<0.05$, respectively). Language production 


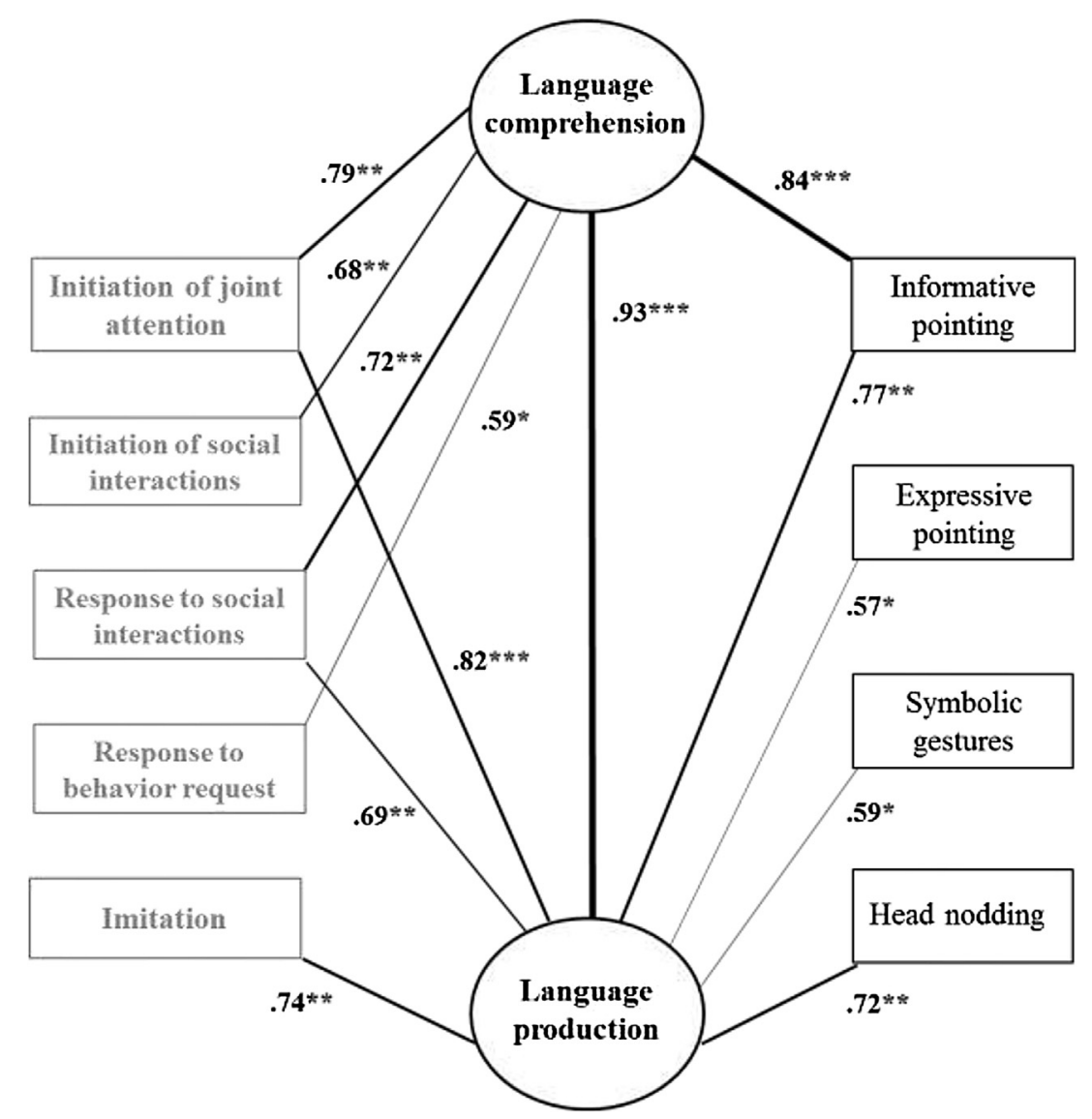

Fig. 1. Language comprehension and production at $\mathrm{T} 1(\mathrm{~N}=13)$ : significant relationships observed with socio-cognitive skills (grey boxes: ESCS scores and imitation) and communicative gestures (black boxes: head nods, informative and expressive points, symbolic gestures).

Table 3

Mean language scores (Lang., comprehension and production) and mean number of gestures produced at T1 and T2 (respectively imperative pointing, expressive pointing, informative pointing, symbolic gestures, showing gestures, head nodding and head shaking). Standard deviations are in parentheses.

\begin{tabular}{|c|c|c|c|c|c|c|c|c|c|}
\hline & Lang. compr. & Lang. prod. & Imp. ptg & Expr. ptg & Infor. ptg & Symb. gestures & Show gestures & Head nod & Head shake \\
\hline $\mathrm{T} 1(N=13)$ & $248.7(154)$ & $166.9(153)$ & $18.2(13.5)$ & $12.1(11.2)$ & $2.15(2.48)$ & $4.08 \quad(3.66)$ & $4.08 \quad(2.96)$ & $4.31(12.7)$ & $2.08(2.53)$ \\
\hline $\mathrm{T} 2(N=8)$ & $388.1(36.1)$ & $331.3(108)$ & $16.1(11.8)$ & $22.3(9.2)$ & $0.75(1.0)$ & 0.63 (1.06) & $(6.5)$ & $4.75(5.4)$ & $2.75(2.3)$ \\
\hline
\end{tabular}

at T1 was correlated to language production at T2, $r s=0.87 ; p<0.01$, but not to language comprehension at $\mathrm{T} 2, r s=0.54$; $p=0.17$.

Scores of social abilities did not significantly differ between T1 and T2 for the six categories assessed with the ECSP (see Table 2), however, when more specific categories were considered separately, the number of giving actions was found to be higher at T1 $(M=11.0, S D=4.6)$ than at T2 $(M=4.9 ; S D=2.7), Z=2.10 ; p<0.05$. Moreover, children produced more gaze alternations between the adult and the object of interest at T2 than at T1, $Z=2.17 ; p<0.05$. Children also followed more frequently the experimenter's gaze at T2 than at T1 (RJA, see Table 2 ), $Z=2.37 ; p<0.05$.

There were no significant differences between T1 and T2 in the frequency of pointing, whatever the function considered, or in the frequency of showing gestures, head nods and head shakes. However, children produced more symbolic gestures at $\mathrm{T} 1(M=2.6, S D=2.9)$ than at $\mathrm{T} 2(M=0.63 ; S D=1.1), Z=2.03 ; p<0.05$.

In addition, the total number of gestures produced at T1 was significantly correlated to language comprehension at T2, $r s=0.71 ; p<0.05$, but not to language production, $r s=0.60 ; p=0.12$. Nevertheless, we found a relationship between language production at T2 and some of the gestures produced at T1: production score was correlated to the amount of expressive pointing, $r s=0.71 ; p=0.050$, and to the amount of informative pointing, $r s=0.83 ; p<0.05$ (but not to the amount of imperative pointing, $r s=0.19 ; p=0.65$ ).

In addition, we created new variables as indicators of individual development between the two sessions, by subtracting the scores obtained at T1 to those obtained at T2. Our goal was to describe the relationships between the socio-cognitive skills assessed with the ESCS, communicative gestures and language level by taking into account the developmental dynamic between the two sessions. Increase in language comprehension score was found to be correlated to the increase in the 
frequency of pointing, $r s=0.71 ; p<0.05$. When each function of pointing was considered separately, the correlation was actually only significant for informative gestures, $r s=0.76 ; p<0.05$. Increase in comprehension score was not correlated to any variation in ESCS scores. Moreover, increase in language production score was not correlated to any difference in the number of gestures produced or in the ESCS scores.

\section{Discussion}

In the present study, we set up semi-structured situations based on the early social communication scale (ESCS) to assess children's communicative profile between 1 and 3 years of age. We focused more specifically on the development of gestural communication by recording the number of gestures produced by children, including giving, showing, pointing and symbolic gestures. We also assessed the form (hand shape) and the function of pointing. Our main objectives were to determine (1) which early socio-cognitive abilities are associated to the development of gestural and verbal communication and (2) whether some kinds of gesture might play a stronger role than others in language acquisition.

Language level was found to be positively and significantly correlated to scores reflecting skills in joint attention, imitation and gestural communication. More specifically, language development was correlated to gaze following and gaze alternation between the recipient and the object or event being referred to. It is of course difficult to address the directionality underlying this relation, but joint attention has long been regarded as an important, though not sufficient, precursor to young children's language acquisition (e.g., Akhtar \& Gernsbacher, 2007; Carpenter et al., 1998), and gaze alternation has been described as a key indicator of referentiality and intentionality, which, in conjunction with other behaviours, may reflect infants' understanding of the adult's attention and intention (e.g., Akhtar \& Gernsbacher, 2008; Moll \& Tomasello, 2004). These capacities may increase the frequency and complexity of interactions, thus further enhancing communication skills: the amount of time infants spend in joint attention with their parents was for example shown to influence pointing onset (Liszkowski, 2011).

Our results also suggest that the role played by children in these interactions impacts on language development: initiation of joint attention was found to correlate with both language comprehension and production, whereas response to joint attention did not correlate either with language comprehension or production. The ability to initiate situations in which one attends to something in common with a communicative partner, both being aware that they are paying attention to the same referent, has indeed been put in relation with infants' developing understanding of others' behaviour and, gradually, with the understanding of the mental states that precede and motivate these behaviours (e.g., Carpendale \& Lewis, 2004; Colonnesi et al., 2008; Heimann et al., 2006; Meltzoff, 1995). Imitation skills may also facilitate the development of language production by promoting affiliation with others; there is growing evidence that imitation is more than a simple transmission process of instrumental skills, which may for example explain the existence of over-imitation in typical development (Nielsen \& Blank, 2011). Moreover, initiation of behavioural requests was correlated neither with language comprehension nor production, suggesting that infants' attempts to elicit a specific action from the adult does not require or support language development. By contrast, the ability to respond to a request from the adult was correlated with language comprehension, but not with language production. The use of the ESCS thus allowed us to identify the communicative skills associated with language level by considering children's role in the interactions.

Another of our objectives was to describe the relationships between the production of gestures and language development. Gestural communication is considered a key precursor to human verbal communication, allowing infants and children to initiate and maintain shared experience with others (e.g., Iverson \& Goldin-Meadow, 2005; Liszkowski, 2008), but this relation may vary according to the kind of gestures taken into account. In the present study, children produced more symbolic gestures (e.g., waving hello, hush gesture, thumb up gesture, etc.) during the first session than during the second one about ten months later, consistent with the idea that verbal language gradually takes over the functions of symbolic communication (e.g., Goodwyn et al., 2000). Moreover, in the first session, the frequency of symbolic gestures was correlated to language production, which could be explained by their common features: symbolic gestures and verbal language refer to a specific and fixed semantic content, resulting from social convention established within interactions. However, symbolic gestures were sometimes difficult to elicit in this experimental context, resulting in a low number of gestures produced. It seems necessary for future studies to think about situations that could trigger spontaneous symbolic gestures, yet in a controlled environment.

The frequency of declarative pointing was also found to increase with language level. Children have previously been reported to use more and more deictic gestures over the second year (e.g., Camaioni, Aureli, Bellagamba, \& Fogel, 2003), but our results have shown that this increase does not apply to imperative pointing. The distinction between these two functions of pointing was also highlighted by a clear difference in hand shapes: imperative pointing was mostly characterized by whole-hand gestures whereas declarative pointing was characterized by index-finger pointing (see Cochet et al., 2014, for a more complete description of morphological differences between imperative and declarative pointing). The relationship between language and declarative pointing was especially strong for declarative informative pointing, both for language production and comprehension, whereas the production of declarative expressive pointing was only correlated with language production. These results, considering first the low number of informative gestures produced by children, and second, the higher inter-individual variability in language production than in language comprehension (O'Reilly, Painter, \& Bornstein, 1997), emphasize the primary importance of declarative pointing compared to imperative pointing in language acquisition (see also Cochet, Jover, \& Vauclair, 2011 and Colonnesi et al., 2010). Declarative pointing, which has been described as a 
universal form of human gestural communication, emerging in all cultures within the same age range (Liszkowski, Brown, Callaghan, Takada, \& De Vos, 2012), may thus appear as a valuable way for young children to build up social, cognitive and motivational skills from which language develops. Informative pointing in particular has been argued to require the ability to coordinate appropriately with a communicative partner, by providing him/her helpful information (Liszkowski et al., 2008).

However, the production of communicative gestures, including declarative pointing, was not significantly correlated to social skills scores. Our results therefore do not support the hypothesis according to which the emergence of declarative pointing relies on early social-cognitive abilities such as imitation and cooperation (e.g., Cochet \& Vauclair, 2010). As cooperation abilities were not correlated to language level in the present study, and yet have been argued by several researchers to play a role in the emergence of language (e.g., Bullinger, Zimmermann, Kaminski, \& Tomasello, 2011; Hamann, Warneken, Greenberg, \& Tomasello, 2011), we can hypothesize that the measures we used were not accurate enough to decipher the complexity of social skills. Further analysis of imitation and cooperation abilities would be needed to tackle this issue, by combining the use of parental questionnaire and direct measures through experimental tasks. Another limitation of our study lies in the small number of participants: although the present results can be considered as a first step that may help identifying directions for future research, their generalization is undoubtedly restricted.

In addition, the frequency of showing gestures was not found to increase with language level, but we did not identify the function of each gesture, as determining the child's intention when he/she presented an object to the adult has proved more difficult than for pointing. Distinguishing between imperative and declarative showing gestures might reveal differences parallel to the ones observed for pointing gestures, and should therefore be considered in future research. Moreover, the production of giving actions was more frequent during the first session than during the second one. Giving an object to the adult is an efficient way for the infant to initiate social interactions, but it provides a rather limited range of communicative possibilities and, contrary to pointing gestures, giving actions may not consistently provoke comments from adults likely to shape infants' linguistic environment and thus favour language acquisition (Kishimoto, Shizawa, Yasuda, Hinobayashi, \& Minami, 2007). Finally, the production of head nods was found to be correlated language production. Toddlers frequently use head gestures to express agreement, and these are not only carried over into the linguistic period but also become more and more coordinated with speech from 18 to 30 months of age (Andrén, 2014). Moreover, children have been reported to produce more agreement messages than refusal ones after 2 years of age (Guidetti, 2005), which might explain why we did not observe the same correlations for head shaking. These gestural forms, primary means of expression for the youngest children, have been argued to be part of language (Andrén, 2014).

\section{Conclusion}

Several researchers have investigated the relationship between early social and cognitive skills, gestural communication and language acquisition, but this study is the first of its kind to analyse specific characteristics of communication abilities, and by considering different categories of gestures (including a description of the form and the function of pointing) and different roles of the children in the interaction (initiation vs. response). Our results have highlighted the importance for young children of initiating joint attention and imitating to develop language, and language production in particular. In addition, the use of declarative expressive pointing, symbolic gestures and head nodding were significantly related to language production, and the use of declarative informative pointing was strongly correlated with the development of both language production and comprehension. These results may have important implications for developmental psychology, as they may allow researchers to improve language evaluation and intervention programs, including for children who present communication disorders.

Because such abilities emerge within interactions, it will be necessary in future studies to also take into account the coordination between caregivers' and children's communicative behaviour. For instance, there seems to be a close relationship between adult's and infant's pointing (Liszkowski et al., 2012), and social feedback from caregivers can influence infants' gesture-vocal combinations (Miller \& Lossia, 2013). The analysis of these interactions, along with a systematic description of gestures and other socio-cognitive abilities such as joint attention, imitation and cooperation, may help getting a more thorough picture of communicative development in the child's first years.

\section{Acknowledgments}

We would like to thank all the children and their parents for participating to this study. This work was supported by a postdoctoral research grant from the Fyssen foundation.

\section{Appendix A. Supplementary data}

Supplementary data associated with this article can be found, in the online version, at http://dx.doi.org/10.1016/j.infbeh.2016.07.003.

\section{References}


Akhtar, N., \& Gernsbacher, M. A. (2007). Joint attention and vocabulary development: A critical look. Language and Linguistics Compass: 1., 195-207.

Akhtar, N., \& Gernsbacher, M. A. (2008). On privileging the role of gaze in infant social cognition. Child Development Perspectives: 2., $59-65$.

Andrén, M. (2014). Multimodal constructions in children: Is the headshake part of language? Gesture: 14., 141-170.

Bates, E., Camaioni, L., \& Volterra, V. (1975). The acquisition of performatives prior to speech. Merrill-Palmer Quarterly: 21., 205-226.

Blake, J., O'Rourke, P., \& Borzellino, G. (1994). Form and function in the development of pointing and reaching gestures. Infant Behavior and Development: 17., 195-203.

Brownell, C., Ramani, G. B., \& Zerwas, S. (2006). Becoming a social partner with peers: Cooperation and social understanding in one- and two-year-olds. Child Development: 77., 804-821.

Bullinger, A. F., Zimmermann, F., Kaminski, J., \& Tomasello, M. (2011). Different social motives in the gestural communication of chimpanzees and human children. Developmental Science: 14., (1), 58-68.

Camaioni, L., Aureli, T., Bellagamba, F., \& Fogel, A. (2003). A longitudinal examination of the transition to symbolic communication in the second year of life. Infant and Child Development: 12., 1-26.

Camaioni, L., Perucchini, P., Bellagamba, F., \& Colonnesi, C. (2004). The role of declarative pointing in developing a theory of mind. Infancy: 5., 291-308.

Capirci, O., Iverson, J. M., Pizzuto, E., \& Volterra, V. (1996). Gesture and words during the transition to two-word speech. Journal of Child Language: 23., $645-673$.

Carpendale, J., \& Lewis, C. (2004). Constructing an understanding of mind: The development of children's understanding of mind within social interaction. Behavioural and Brain Sciences: 27., 79-150.

Carpenter, M., Nagell, K., \& Tomasello, M. (1998). Social cognition, joint attention, and communicative competence from 9 to 15 months of age. Monographs of the Society for Research in Child Development: 255., (63), 1-143.

Charman, T., Baron-Cohen, S., Swettenham, J., Baird, G., Cox, A., \& Drew, A. (2000). Testing joint attention, imitation, and play as infancy precursors to language and theory of mind. Cognitive Development: 15., 481-498.

Cochet, H., \& Vauclair, J. (2010). Pointing gestures produced by toddlers from 15 to 30 months: Different functions, hand shapes and laterality patterns Infant Behaviour and Development: 33., 432-442.

Cochet, H., Jover, M., \& Vauclair, J. (2011). Hand preference for pointing gestures and bimanual manipulation around the vocabulary spurt period. Journal of Experimental Child Psychology: 110., 393-407.

Cochet, H., Jover, M., Oger, L., \& Vauclair, J. (2014). Morphological differences between imperative and declarative pointing: hand shape: arm extension and body posture. Journal of Motor Behavior: 46., 223-232.

Cochet, H., Jover, M., Rizzo, C., \& Vauclair, J. (2016). Relationships between declarative pointing and theory of mind abilities in 3- to 4-year-olds. European Journal of Developmental Psychology, http://dx.doi.org/10.1080/17405629.2016.120597

Colonnesi, C., Rieffe, C., Koops, W., \& Perucchini, P. (2008). Precursors of theory of mind. A longitudinal study. British Journal of Developmental Psychology: 26., 561-577.

Colonnesi, C., Stams, G., Koster, I., \& Noom, M. J. (2010). The relation between pointing and language development: A meta-analysis. Developmental Review: 30., (4), 352-366.

Fenson, L., Marchman, V. A., Thal, D., Dale, P., Reznick, S., \& Bates, E. (2007). MacArthur-Bates Communicative Development Inventories: User's guide and technical manual (2nd ed.). Baltimore, MD: Paul H. Brookes.

Goodwyn, S., Acredolo, L., \& Brown, C. (2000). Impact of symbolic gesturing on early language development. Journal of Nonverbal Behaviour: $24 ., 81-103$.

Guidetti, M., \& Tourrette, C. (2009). Echelle d'Evaluation de la communication sociale Précoce [Early social communication scale]. Paris: Eurotests (First edition 1993)

Guidetti, M. (2002). The emergence of pragmatics: Forms and functions of conventional gestures in young French children. First Language: 22., (3), $265-285$

Guidetti, M. (2005). Yes or no? How do young children combine gestures and words to agree and refuse. Journal of Child Language: $32 ., 911-924$.

Hamann, K., Warneken, F., Greenberg, J., \& Tomasello, M. (2011). Collaboration encourages equal sharing in children but not chimpanzees. Nature: 476. 328-331.

Hamilton, A., Plunkett, K., \& Schafer, G. (2000). Infant vocabulary development assessed with a British Communicative Development Inventory: Lower scores in the UK than the USA. Journal of Child Language: 27.,689-705.

Heimann, M., Strid, K., Smith, L., Tjus, T., Ulvund, S. E., \& Meltzoff, A. N. (2006). Exploring the relation between memory, gestural communication and the emergence of language in infancy: Longitudinal study. Infant and Child Development: 15., 233-249.

Iverson, J. M., \& Goldin-Meadow, S. (2005). Gesture paves the way for language development. Psychological Science: 16., 367-371.

Kishimoto, T., Shizawa, Y., Yasuda, J., Hinobayashi, T., \& Minami, T. (2007). Do pointing gestures by infants provoke comments from adults? Infant Behavior and Development: 30., 562-567.

Kristen, S., Sodian, B., Thoermer, C., \& Perst, H. (2011). Infants' joint attention skills predict toddlers'emerging mental state language. Developmental Psychology: 47., (5), 1207-1219.

Liszkowski, U., \& Tomasello, M. (2011). Individual differences in social, cognitive: And morphological aspects of infant pointing. Cognitive Development: 26., 16-29.

Liszkowski, U., Carpenter, M., Henning, A., Striano, T., \& Tomasello, M. (2004). Twelve-month-olds point to share attention and interest. Developmental Science: 7., 297-307.

Liszkowski, U., Carpenter, M., \& Tomasello, M. (2008). Twelve-month-olds communicate helpfully and appropriately for knowledgeable and ignorant partners. Cognition: 108., 732-739.

Liszkowski, U., Brown, P., Callaghan, T., Takada, A., \& De Vos, C. (2012). A prelinguistic gestural universal of human communication. Cognitive Science: 36. , $698-713$.

Liszkowski, U. (2005). Human twelve-month-olds point cooperatively to share interest with and helpfully provide information for a communicative partner. Gesture: 5., (1-2), 135-154.

Liszkowski, U. (2008). Before L1: A differentiated perspective on infant gestures. Gesture: 8., (2), 180-196

Liszkowski, U. (2011). Three lines in the emergence of prelinguistic communication and social cognition. Journal of Cognitive Education and Psychology: 10., (1)

Meguerditchian, A., Cochet, H., \& Vauclair, J. (2011). From gesture to language: ontogenetic and phylogenetic perspectives on gestural communication and its cerebral lateralization. In A. Vilain, J. L. Schwartz, C. Abry, \& J. Vauclair (Eds.), Primate communication and human language: Vocalisation, gestures, imitation and deixis in humans and non-humans (pp. 89-118). Amsterdam: John Benjamins.

Meltzoff, A. N. (1995). Understanding the intentions of others: Re-enactment of intended acts by 18-month-old children. Developmental Psychology: 31. $838-850$.

Meng, X., \& Hashiya, K. (2014). Pointing behavior in infants reflects the communication partner's attentional and knowledge states: A possible case of spontaneous informing. Public Library of Science: 9., (9), e107579. http://dx.doi.org/10.1371/journal.pone.0107579

Miller, J. L., \& Lossia, A. K. (2013). Prelinguistic infants' communicative system: Role of caregiver social feedback. First Language: 33., (5), 524-544.

Moll, H., \& Tomasello, M. (2004). 12- and 18-month-old infants follow gaze to spaces behind barriers. Developmental Science: 7., 1-9.

Mundy, P., Delgado, C., Block, J., Venezia, M., Hogan, A., \& Seibert, J. (2003). A manual for the abridged Early Social Communication Scales (ESCS). Coral Gables, Florida: Available through the University of Miami Psychology Department. pmundy@miami.edu

Nielsen, M., \& Blank, C. (2011). Imitation in young children: When who gets copied is more important than what gets copied. Developmental Psychology: 47., 1050-1053. 
O’Reilly, A. W., Painter, K. M., \& Bornstein, M. H. (1997). Relations between language and symbolic gesture development in early childhood. Cognitive Development: 12., 185-197.

Özçaliskan, S., \& Goldin-Meadow, S. (2005). Gesture is at the cutting edge of early language development. Cognition: 96., 101-113.

Rodrigo, M. J., González, A., Ato, M., Rodríguez, G., De Vega, M., \& Muñetón, M. (2006). Co-development of child-mother gestures over the second and the third years. Infant \& Child Development: 15., (1), 1-17.

Rowe, M. L., \& Goldin-Meadow, S. (2009). Early gesture selectively predicts later language learning. Developmental Science: $12 ., 182-187$.

Seibert, J. M., Hogan, A. E., \& Mundy, P. C. (1982). Assessing interactional competencies: The early social-communication scales. Infant Mental Health Journal: 3., 244-245.

Tomasello, M., \& Call, J. (1997). Primate cognition. New York: Oxford: University Press.

Tomasello, M., Carpenter, M., \& Liszkowski, U. (2007). A new look at infant pointing. Child Development: 78., 705-722.

Vaughan Van Hecke, A., Mundy, P., Acra, C. F., Block, J., Delgado, C., Parlade, M., .. \& Pomares, Y. B. (2007). Infant joint attention, temperament: And social competence in preschool children. Child Development: 78., 53-69. 